\title{
A Revista Psicologia: Ciência e Profissão: Um Registro da História Recente da Psicologia Brasileira
}

The periodical Psicologia Ciência e Profissão: A recent historical register of the brasylian Psychology

Regina Helena de Freitas Campos

Universidade Federal de Minas Gerais

Lúcia Helena Garcia Bernardes

Universidade José do Rosário Vellano
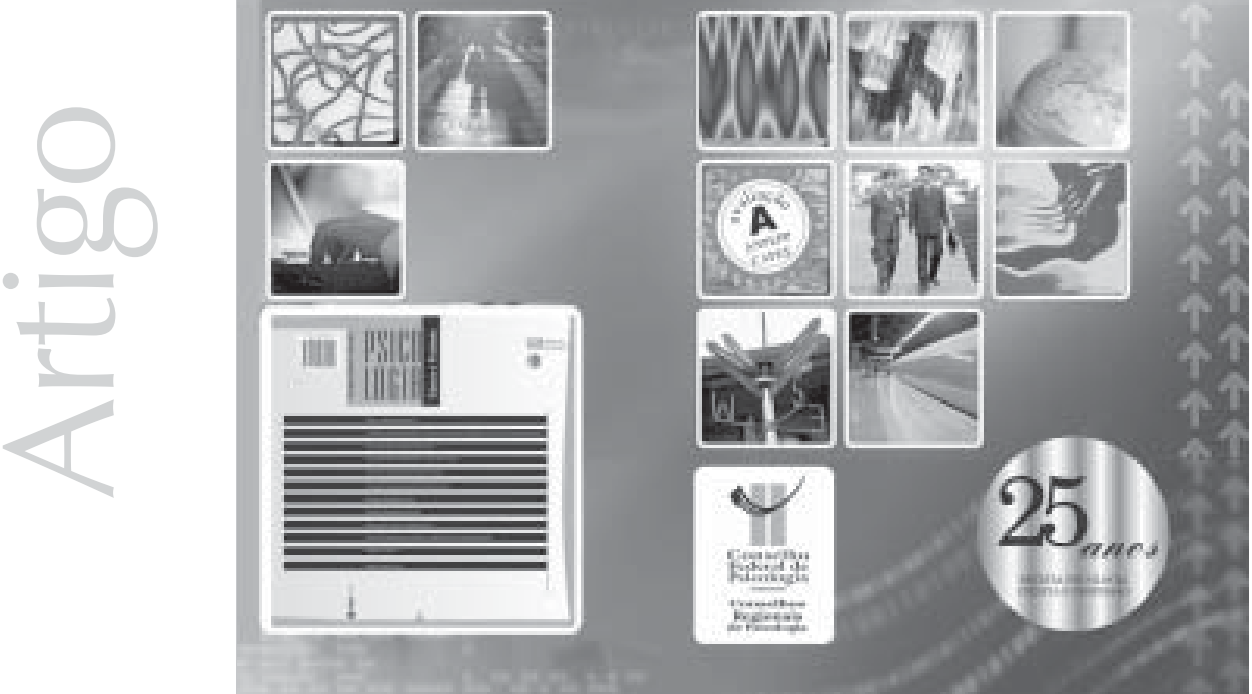


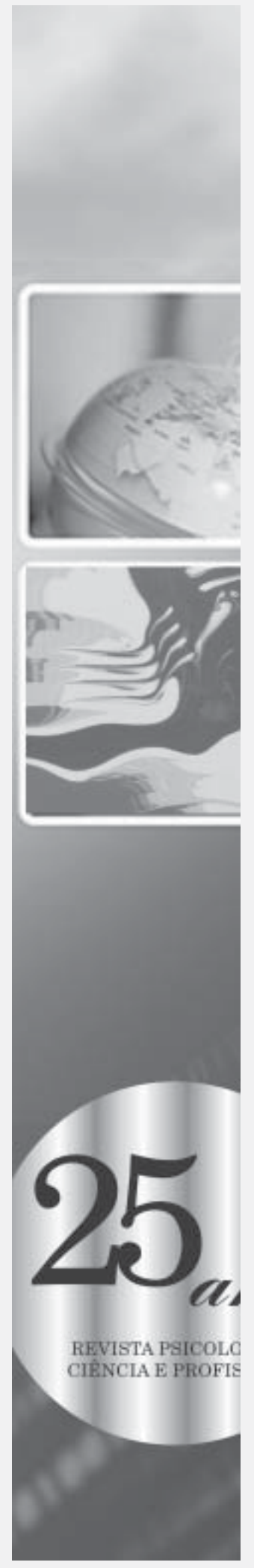

Resumo: A trajetória da Revista Psicologia: Ciência e Profissão, do Conselho Federal de Psicologia, é analisada, no contexto das comemorações de seus 25 anos, evidenciando o processo de transformação que a levou a ser avaliada como periódico de nível A pela CAPES, em 2000, acompanhando as transformações teóricas e práticas da Psicologia no Brasil, atingindo, assim, a excelência em seu campo de atuação. Seu percurso é analisado a partir de dados das seguintes partes da revista: capa, contra-capa, editorial, ficha técnica, sumário, seções e temas dos artigos, utilizando como fontes todos os números publicados entre 1979 e 2004 (56 exemplares). Psicologia: Ciência e Profissão revela-nos os psicólogos como profissionais que escutam a sociedade onde vivem, produtores de práticas que têm, cada vez mais, referência nesta sociedade. Nesses 25 anos, a revista registrou a produção de uma nova identidade para a Psicologia brasileira, construída a partir tanto do diálogo com os diversos campos de atuação quanto da produção de outros olhares sobre esses diversos campos, mostrando como a profissão se deslocou de uma posição mais elitista para uma outra comprometida com a ampliação dos espaços de atuação do psicólogo junto a camadas desprivilegiadas da população brasileira, conhecida como de um maior compromisso social. Palavras-chave: Psicologia: Ciência e Profissão; história da Psicologia no Brasil; Psicologia e compromisso social.

Abstract: The periodical Psicologia: Ciência e Profissão (Psychology: Science and Profession), edited by the Federal Council of Psychology, has been surveyed, in its 25 years of existence, providing evidence for the process of transformation that led it to be evaluated as a level A periodical by CAPES (the Brazilian Ministry of Education Agency) in 2000, thus being considered a leading source of information on Brazilian Psychology, distinguished for its excellence. Its journey is analyzed using as sources the following parts: cover, back-cover, editorial, technical records, table of contents, sections and subjects of the articles. All editions published between 1979 and 2004 were examined, covering 56 numbers. The periodical reveals Brazilian psychologists as professionals who listen to the society they live in and who create relevant practices for this society. Along these 25 years, the review registered the building of a new identity for Brazilian Psychology, stemming from the discussion about its various fields of application and from the production of different views on these fields as well, showing how the profession moved from an elitist position to another one, based on a compromise to enlarge the offering of psychological services to wider parcels of the Brazilian population, thus increasing the social relevance of the profession.

Key words: Psychology: Science and Profession, history of Psychology in Brazil, Psychology and social commitment. 
A revista Psicologia: Ciência e Profissão, publicada pelo Conselho Federal de Psicologia desde 1979, registrou as transformações da Psicologia como campo de conhecimento e de atividades profissionais no Brasil nos últimos 25 anos. Sendo um espaço, por excelência, de divulgação dos trabalhos de psicólogos brasileiros, o periódico contribuiu significativamente para o amadurecimento dessa área do saber.

Até meados da década de 1990, as equipes responsáveis por sua publicação enfrentaram diversas dificuldades operacionais para estabelecer uma periodicidade cientificamente valorizada. A partir do ano de 1997, a revista se consolidou como um espaço privilegiado de divulgação dos trabalhos produzidos por psicólogos no País, e, como a própria Psicologia como ciência e como profissão, tornou-se um espaço maduro de reflexão e diálogo. No ano 2000, a revista foi reconhecida pela CAPES como um periódico de primeira linha, de nível A.

Para contar sua história, bem como afirmar o periódico como um registro da história recente da Psicologia brasileira, procedeu-se a uma análise de todos os seus exemplares, no total de 56, tomando como referência os diversos elementos que os compõem. Foram analisados tanto elementos referentes ao conteúdo, considerando, para isso, os editoriais e os temas desenvolvidos nos artigos, quanto elementos referentes a aspectos técnicos da publicação.

O material foi organizado historicamente. Os números publicados foram divididos em quatro fases, a partir das definições das respectivas linhas editoriais: 1979 a 1983 (ênfase na história da Psicologia e na divulgação da pesquisa em Psicologia feita no Brasil); 1984 a 1991 (ênfase na relevância social dos trabalhos publicados e nas políticas científicas e profissionais definidas para a área da Psicologia no Brasil); 1992 a 1996 (síntese entre a divulgação de trabalhos socialmente relevantes e o atendimento da demanda espontânea pela publicação de artigos científicos ou de relatos de experiências profissionais), e de 1997 a 2004 (ênfase na divulgação de trabalhos de pesquisa de primeira linha, visando à construção de um periódico de referência na área, associada à preocupação com a relevância social). Em cada uma dessas fases, buscou-se identificar as temáticas apresentadas e o formato técnico que o periódico apresenta. As diferentes fases refletem os estágios de amadurecimento da Psicologia como ciência e profissão, no Brasil, revelando o nível de organização da categoria bem como sua crescente inserção social. O papel do Conselho Federal de Psicologia nesse processo de amadurecimento é inquestionável, na medida em que essa autarquia não só projeta e concretiza o periódico como também, por meio dele, leva aos psicólogos a produção da área, possibilitando um processo de identificação positivo com a profissão. A partir de uma atuação ainda limitada nos campos da clínica, da escola e do trabalho, no final dos anos 1970 e início dos anos 1980, podemos ver os profissionais ocupando paulatinamente múltiplos espaços bem como redimensionando sua relação com os espaços tradicionais. De uma ciência essencialmente positivista, que tem no behaviorismo a referência teórica principal e que reconhece a diversidade teórica que a permeia como um problema a ser superado, é possível acompanhar o aprendizado da convivência com a diversidade, tanto no plano teórico quando no plano cultural, de uma forma mais ampla.

\section{Primeira fase (1979-1983): a ênfase na produção científica e na historiografia da área.}

O editorial da primeira edição do periódico, elaborado pelo Conselheiro-presidente, Arthur de Mattos Saldanha, em dezembro de 1979, 
comemora o centenário da fundação do famoso laboratório de Psicologia de Wundt em Leipzig, e destaca como motivações para a iniciativa da publicação a necessidade de fornecer informações ao número crescente de profissionais com formação em Psicologia existentes no País (cerca de 17.000, na época, com possibilidades de crescimento para cerca de 30.000 no início dos anos 1980) e o amadurecimento da área. Afirma que a Psicologia no Brasil teria atingido "níveis científicos e de ensino equivalentes aos das mais renomeadas instituições estrangeiras" e que o País dispunha de "uma cultura em Psicologia que se iguala à melhor tradição européia ou norte-americana, superando-a muitas vezes". Esse amadurecimento do campo podia ser observado na "presença brasileira nos congressos internacionais" e na crescente produção científica, evidenciada no fato de que:

"diferentemente de tempos passados, mas não remotos, não somos nós apenas a procurar lá fora o conhecimento psicológico, senão que dispomos já de um know how psicológico que está sendo buscado e levado a centros outros de além fronteiras. As obras nascidas de autores brasileiros e produzidas a partir de pesquisa aqui realizada hoje ocupam boa parte das estantes de nossas bibliotecas especializadas, e começam a ser vertidas a idiomas outros" (Saldanha, 1979, p. 2).

\section{O editorial lembra também a regulamentação precoce da profissão:}

\footnotetext{
“o Brasil (foi) um dos primeiros países a reconhecer e regulamentar o exercício profissional em Psicologia. (...) Nosso modelo de legislação, nesse particular, tem servido de inspiração a países co-irmãos da América Latina, e mesmo tem sido procurado por psicólogos e agências governamentais de nações situadas do outro lado da linha de Greenwich" (Saldanha, 1979, p.2).
}

Nesse tom otimista, o editorial esclarece o objetivo de que a revista seja um veículo dessa produção brasileira, e a expectativa de "vê-la crescer e persistir no trabalho dos que nos irão suceder neste Conselho (...) e no carinho de nossos colegas psicólogos, espalhados aos milhares pelos brasis de nosso Brasil" (Saldanha, 1979, pp. 2-3).

O volume vem acompanhado de um encarte contendo as normas para apresentação de contribuições, que apresenta a revista Psicologia: Ciência e Profissão como "publicação oficial do Conselho Federal de Psicologia, criada pela Resolução CFP n ${ }^{\circ}$ 026/ 79, de 28 de julho de 1979, com o intuito de representar o pensamento nacional em Psicologia" (CONSELHO FEDERAL DE PSICOLOGIA, s/d, p. 1). Esclarece que se trata de "instrumento de comunicação aberto a todos os psicólogos, propiciando-lhes informação atualizada e de caráter histórico, e apresentando as várias linhas de pesquisa, abordagens e tendências da Psicologia atual, em seus aspectos teóricos, metodológicos e aplicados" (CONSELHO FEDERAL DE PSICOLOGIA, s/d, p.1). O conselho editorial da revista é composto por um representante do Conselho Federal de Psicologia, um representante de cada Conselho Regional (na época, eram oito os regionais), e um representante da Associação Brasileira de Psicologia então existente, sendo assessorado por um corpo de consultores definidos como "especialistas radicados nas diversas regiões do território nacional e representativo, no seu todo, das abordagens e tendências da Psicologia brasileira" (CONSELHO FEDERAL DE PSICOLOGIA, s/d, p. 1) ${ }^{1}$. O encarte apresenta as normas para o preparo de manuscritos, observando que o cânone do trabalho científico deve ser observado, e vem acompanhado de um "questionário", que visa obter dos psicólogos "suas idéias, desejos e aspirações" sobre a revista, esclarecendo que a publicação "pretende ser de todos nós, feita por e para todos nós da classe, e não o "o Brasil (foi) um dos primeiros países a reconhecere regulamentar o exercício profissional em Psicologia. (...) Nosso modelo de legislação, nesse particular, tem servido de inspiração a países co-irmãos da América Latina, e mesmo tem sido procurado por psicólogos e agências governamentais de nações situadas do outro lado da linha de Greenwich"

Saldanha
1 o primeiro conselho editorial da revista é composto por João Cláudio Todorov (representando o CFP), Eunice Soriano de Alencar, Paulo da Silveira Rosas, Antonio Rodrigues Soares, Wanderley Chieppe Felippe, Halina Grynberg, Romeu Almeida, Francisco Pedro Estrazulas Pereira de Souza, Anizio Henrique de Faria Júnior e Eva Nick (representante da Associação Brasileira de Psicologia). 
pensamento de um grupo restrito de pessoas e profissionais". Pretende ser "o início de um diálogo franco e aberto, incessante. Só assim nós nos uniremos no propósito de editar uma revista de Psicologia brasileira, de expressão nacional" (CONSELHO FEDERAL DE PSICOLOGIA, s/d, p. 2).

O número 0, de 1979, traz artigos sobre a préhistória da Psicologia no Brasil, história da Psicologia na Medicina e na educação, legislação, encontros de sociedades de Psicologia, eleição e posse do $1^{\circ}$ e $2^{\circ}$ Plenários do Conselho Federal de Psicologia, o debate entre a chamada Psicologia acadêmica e a prática profissional, e um relato de pesquisa sobre construção de escala de avaliação de concepções parentais. A escolha dos artigos revela o desejo de oferecer aos leitores informações sobre a história e organização da área, os debates da época, e um exemplo de pesquisa científica em Psicologia.

No ano 1980, nenhum outro volume foi editado. No período subseqüente (1981 a 1983), foram editados quatro exemplares, contendo artigos científicos e ensaios teóricos. A composição do conselho editorial permanece a mesma, com algumas poucas substituições. A maior parte dos artigos publicados no período se situa nas áreas da Psicologia da aprendizagem (a partir da abordagem comportamentalista) e da Psicologia do desenvolvimento (com ênfase na abordagem da Psicologia genética). As áreas mais aplicadas comparecem com alguns poucos artigos, sobre Psicologia do trânsito, psicoterapia, Psicologia escolar, Psicologia de grupos, toxicomania. As questões relativas à formação ou profissionalização dos psicólogos ocupam dois artigos, bem como as preocupações mais teóricas, evidenciadas em artigos sobre história da Psicologia e questões epistemológicas.

\section{Segunda fase (1984-1991) - e a realidade brasileira?}

A partir de 1984, uma nova comissão editorial assume a responsabilidade pela edição da revista e promove mudanças profundas no formato e na definição da linha editorial. A revista passa a se definir como "destinada a veicular reflexões a respeito do conhecimento e da prática da Psicologia, voltados para o desenvolvimento de teorias, métodos e técnicas aplicáveis à realidade brasileira" (PSICOLOGIA: CIÊNCIA E PROFISSÃO, 1984, vol. 4, n. 1, p. 4). A comissão editorial deve zelar para que a revista promova essas reflexões e seja amplamente divulgada entre os psicólogos. Observa-se que "a revista não se obriga a publicar textos que não se enquadrem em sua linha editorial" (PCP, 1984, vol. 4, n. 1, p. 4) ${ }^{2}$, embora todos os textos recebidos devam ser examinados e o resultado da análise comunicado aos autores. A comissão editorial fica composta por um grupo de psicólogos ${ }^{3}$ indicados pelo Conselho Federal ou Conselhos Regionais, não havendo mais a representação da Associação Brasileira de Psicologia.

A carta editorial apresenta uma "nova linha editorial", inspirada nos "ventos da mudança social (que) sopram entre nós" (PCP, 1984, vol. 4, n. 1, p. 4). A mudança social indicada refere-se, certamente, ao processo de redemocratização em curso no País, com o fim do regime militar (1964-1984). A maior liberdade de expressão faz emergir as preocupações da comunidade dos psicólogos relacionadas à sua participação no processo político e na ênfase na necessidade de atendimento a demandas de parcelas mais amplas da população. O editorial observa que:

"a categoria profissional dos psicólogos não poderia permanecer insensível diante desses 'sinais dos tempos', pois é nesse horizonte rico de esperanças e contradições que constituímos nossa ciência e exercemos nossa profissão" (PCP, 1984, vol. 4, n. 1, p. 4).

A revista se propõe a ser menos acadêmica, tornando-se veículo mais ágil e flexível, passando a aceitar, além de relatos de pesquisa, reportagens, opiniões de leitores, transcrições 
de mesas-redondas, entrevistas, resenhas de teses e de livros. Além disso, a nova comissão editorial tenciona "ir ao encontro das preocupações de nossa categoria profissional, trabalhando no sentido de produzir o conteúdo da revista, de modo a suscitar novas temáticas, estimulando estudos, interrogações e polêmicas", com o objetivo de "veicular uma diversidade de temas e de modos de produzir o conhecimento" (PCP, 1984, vol. 4, n. 1, p. 4). O objetivo é "a mediação entre a reflexão e a pesquisa universitárias e as inquietações da comunidade" (PCP, 1984, vol. 4, n. 1, p. 4). Enfatiza-se também que é necessário que a revista se torne um espaço interdisciplinar, no qual

"a procedência múltipla dos enfoques possa fecundar-se. Esperamos aportes provenientes de outras áreas e disciplinas, certos de que a interpenetração dos diversos campos das ciências é não só inevitável mas também desejável, pois a compartimentalização dos saberes responde, antes, às demandas da burocracia do que às necessidades do conhecimento" (PCP, 1984, vol. 4, n. 1, p. 5).

Reconhecem os editores, porém, que "essa abertura externa à interdisciplinaridade exige, por sua vez, uma abertura interna, na direção de uma ampla tolerância epistemológica" (PCP, 1984, vol. 4, n. 1, p. 5, g.n.). Define-se a Psicologia como um espaço teórico e prático atravessado "por uma heterogeneidade de técnicas, métodos e abordagens, que os torna irredutíveis a uma cientificidade comum, a não ser que se recorra a uma exclusão de princípio" (PCP, 1984, vol. 4, n. 1, p. 5). Os critérios escolhidos para a seleção de contribuições dentro da nova linha editorial são, pois:

"relevância temática para toda (a) categoria profissional, utilização de uma linguagem não excessivamente técnica ou especializada, descrição e análise de problemas fundamentais e não de questões secundárias e de alcance restrito, apresentação de trabalhos de caráter sintético, que não se estendam em detalhar longamente procedimentos e resultados (PCP, 1984, vol. 4, n. 1, p. 5).

Para os editores, esses critérios garantiriam o propósito de fazer da revista "um lugar de convergência, onde a dispersividade intrínseca da Psicologia se encontre num diálogo crítico" (PCP, 1984, vol. 4, n. 1, p. 5).

Os artigos publicados refletem a nova orientação da revista, abordando temáticas como a predominância das mulheres na profissão, a sindicalização dos psicólogos, políticas de saúde pública, trabalhos de psicólogos em comunidade, Psicologia de grupos excluídos, além de seção dedicada à memória da Psicologia no Brasil. A revista passa também a trazer informes sobre normas de publicações científicas e sobre fontes de informação em Psicologia (bibliotecas, periódicos), estimulando os psicólogos a relatarem suas experiências e reflexões.

A mudança na linha editorial parece ter sido bem recebida pela comunidade dos psicólogos. No segundo volume, editado em 1984, a comissão editorial é mantida, bem como a linha editorial definida no número anterior. A edição traz artigos científicos sobre atuação psicológica e determinantes do comportamento humano. Novas seções são inauguradas: a seção Psicologia em Debate, de responsabilidade da comissão editorial, visando "colocar em discussão questões relevantes em nosso meio profissional" (PCP, 1984, vol. 4, n. 2, p. 5); uma matéria sobre "temas vivenciados no dia a dia do trabalho profissional", no caso, o depoimento de quatro psicólogas sobre o tema "Eu, mulher, psicóloga e negra"; uma nova seção intitulada Contraponto, como "espaço para a exposição de um ponto de vista teórico, técnico ou filosófico que, divergindo de algum modo do artigo a que se refere, permite apontar discussões" (PCP, 1984, vol. 4, n. 2, p. 5); 
4 Fúlvia Rosemberg deixa a comissão em 1985; Thereza Mettel e Marcos Jardim, em 1986, sendo substituídos por Eulina Lordelo, Mercedes Cunha Chaves de Carvalho e Paulo Maldos. Em 1987, Sérgio Antonio da Silva Leite substitui Vera Lúcia Colucci como presidente da comissão. Em 1989, Vera Lúcia Colucci volta a fazer parte da comissão, com Maria do Carmo Vieira e Marisa Eisirik, substituindo Eulina Lordelo, Mercedes Cunha Chaves de carvalho e Paulo Maldos.

5A Tabela 1 (em anexo) mostra a evolução das tiragens da Revista Psicologia: Ciência e Profissão: uma seção de entrevistas e depoimentos de psicólogos pioneiros na profissão, denominada Memória Viva; uma seção de informações científicas; uma seção permanente destinada a veicular notícias profissionais ou científicas sobre livros, teses, atividades, revistas técnicas, escalas padronizadas recentemente, monografias e levantamentos bibliográficos feitos em determinadas áreas da Psicologia, denominada Acontece, e, finalmente, uma seção de resenhas de livros ou teses. Há ainda uma seção de Cartas, cuidadosamente respondidas, a maioria delas comentando os novos rumos da revista e fazendo sugestões quanto ao formato e distribuição.

No período subseqüente (1985 a 1991), a comissão editorial permanece estável, com algumas pequenas modificações ${ }^{4}$. O formato da revista privilegia o diálogo com a comunidade (seções Cartas, Depoimentos); os artigos abordam, em sua maioria, temas relacionados à realidade social, os debates sobre temas emergentes na Psicologia, especialmente na área mais aplicada, e as seções informativas trazem dados sobre novas publicações e periódicos científicos, eventos, instituições relevantes na área. Os artigos, depoimentos e debates assumem predominantemente perspectiva crítica, e os editoriais buscam dialogar com os leitores, orientando-os acerca das preocupações predominantes entre os profissionais e sobre a necessidade de ampliação da participação dos psicólogos nos debates de questões sociais importantes no País (movimentos sociais, processo constituinte de 1988), reafirmando a necessidade de tornar o periódico realmente nacional. A partir de 1986, a revista passa a registrar a tiragem de cada exemplar, que, nesse ano, chega a 50.000, procurando atingir todos os psicólogos inscritos nos Conselhos Regionais então existentes ${ }^{5}$.

Em 1987, o periódico passa por dificuldades financeiras devido aos problemas provocados pelas políticas econômicas do governo federal, mas amplia a edição para 55.000 exemplares. O segundo exemplar, de 1987, com 64.000 exemplares impressos, volta a discutir as questões profissionais dos psicólogos no contexto dos problemas da sociedade brasileira e manifesta preocupação com a imagem desse profissional junto à população. O editorial festeja os 25 anos da regulamentação da profissão, observando que esta foi o resultado de 30 anos de lutas de profissionais que já atuavam como psicólogos, representando "uma grande conquista de nossa categoria que, na época, já começava a se organizar e marcar presença na sociedade brasileira". A seguir, durante os anos da ditadura militar (19641984), "os profissionais de diversas áreas foram praticamente impedidos de participar na discussão e encaminhamento de soluções para os principais problemas sociais que atingiam nossa população". Os anos 1980 mostraram o amadurecimento da categoria, seja na organização, seja na busca de novas formas de atuação socialmente relevantes. Entretanto, a imagem da profissão junto à população não se alterou; os psicólogos continuaram a ser percebidos como profissionais que cuidam de pessoas com problemas "de cabeça", imagem essa derivada do tipo de atuação privilegiada. O editorial identifica como desafio mudar essa imagem, para que o psicólogo seja percebido como profissional socialmente importante, pelo "exercício de práticas profissionais que efetivamente atendam às necessidades de todos os setores sociais, principalmente dos setores majoritários, isto é, das populações mais pobres". Isso deveria ser feito pelo aprofundamento do "processo de revisão crítica sobre o tipo de conhecimento que temos produzido e a busca de novos modelos de atuação mais adequados para a nossa realidade" e pelo fortalecimento das organizações profissionais, com a participação ativa dos psicólogos. Por fim, a revista reafirma seu papel como "canal de socialização de idéias, conhecimentos e propostas de atuação", e solicita a colaboração dos leitores para que enviem artigos relatando atividades profissionais 
socialmente relevantes e inovadoras ou pesquisas que mereçam ser divulgadas amplamente. Conclui dizendo que a socialização de novos conhecimentos e práticas profissionais é uma estratégia fundamental para a reconstrução da imagem social dos psicólogos (PCP, 1987, vol. 7, n.2, p. 4).

Nos anos seguintes, a revista continua a veicular matérias que discutem tanto as definições epistemológicas da área quanto os trabalhos dos psicólogos que contribuem para ampliar o campo de atuação profissional e para a democratização dos serviços psicológicos prestados à população. Busca-se focalizar temas socialmente relevantes, reafirmando a publicação como espaço de análise dos problemas sociais, de crítica social e de socialização de experiências inovadoras com populações excluídas. Discute-se também sobre os currículos dos cursos de Psicologia no País, considerados muito teóricos e afastados das questões sociais mais prementes que desafiam os psicólogos. Em 1989, os resultados da pesquisa "Quem é o psicólogo brasileiro" (CONSELHO FEDERAL DE PSICOLOGIA, 1988), promovida pelo CFP, motivam a discussão da predominância da atividade clínica, a partir do modelo médico, e o pouco comprometimento da categoria com setores populares, cujo resultado seria o acesso aos serviços do psicólogo apenas às camadas economicamente privilegiadas, diminuindo a relevância social do profissional por sua contribuição limitada à superação dos "problemas que afetam amplas camadas da população" (PCP, 1989, vol. 9, n. 2, p. 4). Reafirma-se a necessidade de buscar novas formas de atuação profissional, inclusive na área clínica, visando à democratização dos serviços de Psicologia. Embora ainda com problemas financeiros e dificuldades em manter a periodicidade, a revista continua a ser publicada, às vezes reunindo vários fascículos em um único exemplar.
Em 1990, focaliza-se o tema da atuação profissional do psicólogo nas organizações, ainda comentando os dados da pesquisa Quem é o Psicólogo Brasileiro (CONSELHO FEDERAL DE PSICOLOGIA, 1988). O editorial do primeiro fascículo de 1990 destaca o fato de que a área denominada Psicologia organizacional, industrial ou do trabalho tem sido vista com "muita 'reserva' por vários setores extra e intra-categoria"; com freqüência, os psicólogos organizacionais têm sido criticados por "atenderem apenas aos interesses do capital em detrimento dos trabalhadores assalariados". Prossegue afirmando que, apesar dessa crítica, é nessa área que o psicólogo pode contribuir "para a melhoria das relações entre capital e trabalho, em função de uma sociedade mais justa". Por fim, aponta a possibilidade de que o impasse da Psicologia diante desses interesses divergentes — capital e trabalho — já esteja sendo superado na prática (PCP, 1990, n. 1, p. 3).

Os fascículos 2, 3 e 4 de 1990 são publicados já sob a responsabilidade de nova comissão editorial, indicada pelo Plenário recém-eleito ${ }^{6}$. A nova comissão mantém a definição da revista herdada do período anterior por um curto espaço de tempo (1990-1991), mas passa a publicar preferencialmente artigos e alguns poucos relatos de experiências de trabalho de psicólogos. O segundo exemplar de 1990 apresenta o tema das relações entre o exercício/identidade da Psicologia e as mudanças da sociedade brasileira. "A questão é: o que é Psicologia hoje e como expressarse efetivamente". Inicia a reflexão destacando que "nossa presença no mundo significa intervir nas variáveis culturais e psicológicas à procura de uma equilibração que redunde em bemestar e em saúde para a comunidade". Nessa afirmação, já transparece a presença da orientação sociohistórica que, a partir daí, como poderemos reconhecer nos artigos dos anos seguintes $^{7}$, vai ganhando um significativo espaço entre as abordagens teóricas que sustentam as práticas psicológicas no Brasil. Já
6 A nova comissão editorial é composta pelos psicólogos José Estanislau Vilela, Jorge Ponciano Ribeiro, Paulo Rosas, Liana Gonçalves Pontes Sodré, Jacques Akerman, Vera Maria Ramos de Vasconcelos, João Augusto Frayze Pereira, Maria Lúcia Tiellet Nunes e Esmeralda Aparecida Colombo de Medeiros. Nos no. 3-4 de 1992, acrescentam-se os nomes de Denise Cipriano Jabour e Antônio Olívio Rodrigues.

7 Cf. BERNARDES, L. H.G. Subjetividade: um Objeto para uma Psicologia Comprometida com o Social. 2005. $337 \mathrm{f}$. Tese em Educação. Faculdade de Educação, Universidade Federal de Minas Gerais, Belo Horizonte, 2005. 
podemos reconhecer também o tema saúde como um norteador dessas práticas.

Em 1991, apenas um volume é editado, com 73.000 exemplares, contendo os fascículos 1, 2, 3 e 4. O editorial tem como subtítulo "Ética, perplexidade e cotidiano". O texto destaca a "crise ética" por que passa a sociedade brasileira e discute o conceito de normal como aquilo que deve ser igual e, portanto, repetir-se em todos os seres humanos. Essa forma de compreender a normalidade será substituída pela compreensão do normal como a diferença que cada um revela. Nos anos seguintes, essa idéia será desenvolvida nos artigos sobre o tema inclusão.

O período analisado evidencia como a revista foi progressivamente integrando as temáticas relacionadas à realidade brasileira, à discussão sobre a relevância social, à democratização do trabalho do psicólogo e à reflexão sobre as questões éticas e epistemológicas que atravessavam o trabalho e a investigação científica na área da Psicologia, buscando inclusive a escuta de profissionais de áreas correlatas.

Terceira fase (1992-1996) - ênfase na história da ciência psicológica e da profissão temperada com preocupações sociais e aceitação da diversidade de pontos de vista.

O terceiro período da revista se caracteriza por uma síntese entre o projeto original - a publicação de artigos científicos tratando de perspectivas históricas e do avanço do conhecimento na área da Psicologia - e o projeto de trazer ao debate as questões relacionadas à relevância social do trabalho dos psicólogos. Aparece, também, a ênfase na necessidade de aceitação da diversidade de pontos de vista e de referenciais de análise presentes na área. Essas orientações aparecem em nova definição das normas da revista, que passa a propor a veiculação de matérias com as seguintes características: "(matérias) envolvendo o conhecimento e a prática da Psicologia no Brasil, aceitando contribuições dos seguintes tipos: estudos teóricos/ensaios, relatos de pesquisa, depoimentos/relatos de experiências profissionais, comunicações de pesquisa ou de trabalhos apresentados em eventos e comentários e réplicas a textos publicados em números anteriores" (PCP, 1992, n. 1, p. 39).

Os artigos serão submetidos à revisão cega por pares, e a revista não se responsabiliza pela opinião expressa pelos autores.

A primeira edição de 1992, já com as novas normas editoriais, focaliza estudos sobre as obras de pioneiros da Psicologia no Brasil, podendo-se reconhecer um movimento no sentido de valorizar a produção de psicólogos brasileiros, contribuindo, assim, para a construção de uma identidade profissional positiva, valorizada pela classe (PCP, 1992, vol. 12, n. 1). A segunda edição de 1992 também aborda a história da Psicologia no Brasil, do ponto de vista da regulamentação da profissão. O editorial tem como subtítulo "Política e instituições", e apresenta os temas da edição: a lembrança dos 30 anos da Lei no 4119 , de 1962, os aspectos políticos da profissionalização e a prática da Psicologia em diferentes contextos institucionais. O tom do editorial é bastante crítico, embora comentando a ampliação do campo e o sucesso da profissão (PCP, 1992, vol. 12, n. 2, 1992, p. 3).

O volume seguinte contém os fascículos 3 e 4, e atinge a marca de 78.000 exemplares. O editorial retoma as preocupações sociais e apresenta o tema da edição - os excluídos ao longo da história e na atualidade, observando que:

"hoje, como ontem, o acesso aos bens da vida, aos progressos da ciência, à descoberta do mundo alfabetizado e "culto", à liberdade para pensar e criar, é privilégio dos cidadãos que 
escaparam da capitis diminutio imposta pelas camadas dominantes" (PCP, 1992, vol. 12, n. 3-4, 1992, p. 3).

Observa que essa edição busca definir e caracterizar a categoria dos excluídos, focalizando alguns deles - os deficientes, os sem casa, os sujeitos de camadas populares e "nos obriga a pensar" (PCP, 1992, vol. 12, n. 3-4, 1992, p. 3).

Em 1993, os problemas financeiros continuam a prejudicar a edição da revista, pois apenas um volume é editado, contendo os fascículos $1,2,3$ e 4, com tiragem de 85.000 exemplares. A comissão editorial permanece a mesma, designada desde 1991, e agora conta com a colaboração da Câmara de Comunicação Social do CFP ${ }^{8}$. O tema do volume é "Criança", e o editorial comenta que "a realidade brasileira é imbatível em sua dramaticidade", fazendo referência à "tragédia sociopolítica" (certamente o impeachment do Presidente Fernando Collor) e à sucessão de fatos violentos que chocavam o País, como a chacina do Carandiru, em São Paulo, ou o assassinato de meninos de rua na Candelária, no Rio de Janeiro. No entanto, destaca o papel da pesquisa e da atuação em Psicologia para fazer face a esse drama social brasileiro, ao afirmar que:

"em diversos recantos do Brasil, enquanto alguns tentam resolver a questão à bala, há quem procure entender a realidade da criança através da pesquisa e do estudo, numa tentativa séria de diminuir o sofrimento de um enorme contingente da população brasileira" (PCP, 1993, vol. 13, n. 1-4, p. 3).

A partir de 1994, a revista continua a focalizar a "realidade brasileira" de forma crítica, apresentando tanto artigos temáticos quanto conteúdos diversificados, ampliando, assim, o leque de "idéias e discussões". Essa orientação decorre da necessidade da divulgação de bons trabalhos que não se enquadram em um tema específico, considerando-se que os psicólogos se interessam e enxergam a Psicologia por ângulos, teorias, metodologias e aplicações diferentes. Dessa forma, a revista explicita a questão da diversidade teórica e prática e oferece aos psicólogos brasileiros uma oportunidade de diálogo com essa característica do campo de conhecimento da Psicologia.

No ano 1995, a revista é, pela última vez, publicada em volume único, reunindo os números 1, 2 e 3. A comissão editorial, que, no número anterior, apresenta-se com cinco representantes dos Conselhos Regionais, nesse volume apresenta apenas quatro representantes regionais e um representante do Conselho Federal ${ }^{9}$.

A partir do ano de 1996, o periódico volta a ser publicado em fascículos individuais, tendo os números 1 e 2 a tiragem de 93.000 exemplares, e o número 3, a tiragem de 98.000. A comissão editorial passa a ser composta por seis membros ${ }^{10}$, sem especificação dos Conselhos Regionais de origem de cada um deles, e é recomposta no número $3^{11}$, no qual a especificação de origem volta a constar.

Para apresentar o no 1 de 1996, o editorial dá visibilidade ao processo que originou uma "nova etapa" da revista, na qual se busca dar maior agilidade à aprovação de manuscritos, visando regularizar a periodicidade da revista. O volume inicia essa nova etapa, com artigos temáticos e não temáticos. (PCP, 1996, vol. 16, n. 1, p. 3). Essa apresentação dá a entender que existe uma tensão na produção da revista entre uma orientação que pretende privilegiar o debate sobre a inserção social do trabalho dos profissionais e a demanda espontânea pela publicação de artigos científicos com temáticas variadas. $\mathrm{O}$ conselho editorial propõe a síntese das duas tendências.

O editorial do no 2 de 1996 e o próximo ainda tratam da questão das dificuldades para se
8 Constituida pelos psicólogos Ricardo Figueiredo Moretzsohn, Roseane Korff Wagner e Anizio Henrique de Faria Júnior.

9 A comissão editorial de 1995 é constituída pelos psicólogos Thereza Pontual de Lemos Mettel (CRP-O1), Carlos Roberto Drawin (CRP-06), Maria Lúcia Tiellet Nunes (CRP-O7), Emmanuel Zagury Tourinho(CRP-10) e Ricardo Figueiredo Moretzsohn (CFP).

10 Antônio Marcos Chaves; Emmanuel Zagury Tourinho; José Estanislau Vilela; Maria Lúcia Tiellet Nunes; Odair Sass e Sérgio Antônio Leite.

11 Emmanuel Tourinho (PA); $\quad$ Liliane Froemming (RS); Lúcio Marzagão (MG); Odair Furtado (SP); Paulo Rosas (PE) e Thereza Mettel (DF). 
12 Emmanuel Zagury Tourinho (PA); Francisco José Machado Viana (MG); Liliane Seide Froemming (RS); Lúcio Roberto Marzagão (MG); Odair Furtado (SP); Paulo da Silveira Rosas $(P E)$ e Thereza Pontual de Lemos Mettel (DF).

13 Emmanuel Zagury Tourinho (PA); Francisco José Machado Viana (MG), Liliane Seide Froemming (RS); Lúcio Roberto Marzagão (MG); Paulo da Silveira Rosas (PE) e Thereza Pontual de Lemos Mettel (DF).

14 Emmanuel Zagury Tourinho (PA); Francisco José Machado Viana (MG), Liliane Seide Froemming (RS); Lúcio Roberto Marzagão (MG); Paulo da Silveira Rosas (PE) ; Thereza Pontual de Lemos Mettel (DF) e Sérgio Antônio da Silva Leite (SP).

15 Sérgio Antônio da Silva Leite (SP) - editor responsável; Emmanuel Zagury Tourinho (PA); Liliane Seide Froemming (RS); Lúcio Roberto Marzagão (MG); Paulo da Silveira Rosas (PE). Thereza Pontual de Lemos Mettel (DF).

16 Sérgio Antônio da Silva Leite (SP) - editor responsável; Anna Carolina Lo Bianco (RJ); Louise Lhullier (SC); Paulo da Silveira Rosas (PE), Thereza Pontual de Lemos Mettel (DF) e José Carlos Simões Fontes (PA).

17 Marilene Proença (CFP) - editora responsável. manter a periodicidade da revista bem como da publicação de números temáticos, como é o propósito da linha editorial que está sendo implementada. Os leitores são estimulados a enviar trabalhos para publicação, destacando-se o fato de que poucas revistas científicas no País podiam contar com a infra-estrutura e os meios necessários para assegurar a continuidade da publicação, e, entre elas, podia-se citar o caso do periódico Psicologia: Ciência e Profissão. Observa-se ainda o "público inigualável" da revista - quase cem mil leitores, na medida em que ela é distribuída gratuitamente a todos os psicólogos brasileiros inscritos nos CRPs (PCP, 1996, vol. 16, n. 2, p.3).

O no 3 de 1996 é apresentado sob a responsabilidade da nova comissão editorial, citada anteriormente, que pretende, tal como a anterior, "colocar em dia o calendário de publicações". A revista continua com o formato híbrido, com seção temática e seção não temática. A temática escolhida para esse número foi a Avaliação Psicológica, em função de ter sido pautada pelo II Congresso Nacional de Psicologia. Os artigos abordam temas variados, e esse número pode ser considerado um número de transição entre o projeto de priorizar temas específicos e o atendimento à demanda espontânea (PCP, 1996, vol. 16, n. 3, p. 3).

Assim, parece que a revista, cada vez mais, estimula os leitores a se apropriarem do seu espaço. Ao mesmo tempo, o próprio amadurecimento da área faz com que artigos sobre temas variados alcancem a publicação, favorecendo sua consolidação como um dos periódicos de referência na área no Brasil, como se verá a seguir.

Quarta fase (1997 - 2004) - ênfase na divulgação de trabalhos de pesquisa de primeira linha, visando à construção de um periódico de referência na área, associada à busca de relevância social.
A quarta fase da revista Psicologia: Ciência e Profissão revela um projeto editorial maduro, resultante do trabalho dos grupos que projetaram a revista e dos que a implementaram. A implementação do projeto inicial bem como das modificações que dele decorreram foi um trabalho coletivo realizado pela categoria de psicólogos brasileiros e orquestrado pelos plenários do CFP e pelas sucessivas comissões editoriais que, ao longo dos anos, tomaram a produção de uma revista científica de alto nível como um dos principais objetivos a serem atingidos. Os editoriais da quarta fase são um reflexo da maturidade do periódico bem como da própria categoria de psicólogos, na medida em que descrevem um processo de produção organizado, que tanto cumpre um planejamento quanto se abre para as variações decorrentes do movimento da sociedade.

Em 1997, a comissão editorial sofre duas alterações, no número $1^{12}$, com a entrada de mais um membro, e no número $2^{13}$, quando ocorre a saída de um dos participantes. Essa composição se mantém até o número 2 de 1998, e, no número $3^{14}$ desse ano, o conselho editorial volta a ser composto por sete membros, mantendo-se dessa forma até o número 2 de 1999. Passa por uma alteração no número 3, quando a revista começa a ter um editor responsável ${ }^{15}$ e cinco membros na comissão editorial. Mantém-se assim até o número 3 do ano de 2000, sendo que, a partir do número 1 desse mesmo ano, passa a ter consultores ad hoc. No número 4 do ano 2000, essa composição é novamente refeita, sem alterar o editor responsável ${ }^{16}$.

No número 2 do ano 2002, o grupo é novamente alterado com a mudança do editor responsável $^{17}$. Os consultores ad hoc, que inicialmente são em número de sete, em 2002, já são onze participantes, sendo que, dentre eles, encontram-se antigos membros da comissão editorial. No número 3 de 2002, os consultores ad hoc passam a vinte e um 
participantes e, dos cinco membros da comissão editorial, dois são substituídos ${ }^{18}$. A editora responsável e a comissão editorial permanecem até a quarta edição de 2004, e o número de consultores ad hoc tem um aumento significativo, chegando, nesse último número da revista, publicado no final do ano de 2005, a oitenta e dois participantes. Esse grande aumento no número de consultores ad hoc responde à diversificação dos temas apresentados nos artigos enviados para publicação, como será visto a seguir.

Nessa quarta fase, consolida-se o movimento no sentido da valorização dos pioneiros da Psicologia brasileira. Desde o no 1 de 1997, de forma ininterrupta, são apresentadas biografias de profissionais oriundos de diversos campos do saber e que contribuíram decisivamente para a construção da Psicologia como ciência e profissão no Brasil. Essa sessão apresenta as seguintes biografias: Manuel Bergström Lourenço Filho; Pedro Parafita de Bessa; Annita de Castilho Marcondes Cabral; Madre Cristina Sodré Doria; Elisa Dias Veloso; Carolina Bori; Mira Y Lopes; Agostini de Villalba Alvin; Irmão Henrique Justo; Helena Antipoff; Franco Lo Presti Seminério; Anita Paes Barreto; Reinier Johannes Antonius Rozestraten; Antônio Gomes Penna; Paulo Rosas; Odete Lourenção Van Kolck; Hélio Pelegrino; Nise da Silveira; Ulisses Pernambucano; Dante Moreira Leite; Arthur Ramos; Sílvia Lane; Ofélia Boisson Cardoso; Oswaldo de Barros Santos; André Jacquemin; Eliezer Schneider; Maria Helena Novaes Mira e Durval Marcondes.

Na maturidade, a revista Psicologia: Ciência e Profissão presta homenagem àqueles que estabeleceram esse campo de saber no Brasil e revela seu caráter interdisciplinar. Entre os homenageados, estão os profissionais que trabalharam para a regulamentação da Psicologia como profissão, em nosso país, o que se concretizou em 1962. Advogados, médicos, cientistas sociais e educadores de formação apaixonaram-se pela Psicologia e a ela dedicaram suas vidas de trabalho, colaborando para transformá-la em um campo profissional regulamentado.

Entre os anos de 1997 e 1999, a periodicidade da revista é quadrimestral; em 1998, a tiragem ultrapassa os 100.000 exemplares, e os editoriais ganham o seguinte perfil: apresentação do tema central, seguido de comentários sobre os artigos. Alguns desses temas referem-se aos prêmios monográficos instituídos pelo CFP a partir de 1997, a cada ano homenageando um dos pioneiros da Psicologia no Brasil e a sua área de pesquisa e de atuação profissional. O formato dos prêmios monográficos permite a escolha de artigos de alta qualidade sobre temas de grande relevância social, escolhidos por comissões de especialistas nomeadas pelo próprio plenário do Conselho Federal. Assim, a combinação entre qualidade científica e relevância social buscada de forma persistente pelo periódico é mantida. Além disso, os prêmios permitem acolher contribuições das mais diversas regiões do País, escritos de profissionais, pesquisadores e estudantes que repercutem as preocupações dos psicólogos brasileiros.

A primeira edição de 1998 apresenta os vencedores do Prêmio Monográfico de 1997, que homenageou a psicóloga e educadora Madre Cristina Sodré Doria. Os artigos versam sobre o tema: "Psicologia, Direitos Humanos e Sofrimento Mental". Em 1999, são apresentadas as monografias vencedoras do Prêmio Monográfico Mira y Lopes, cujo tema foi a "Psicologia nas Organizações". A psicóloga e educadora Helena Antipoff é homenageada no Prêmio Monográfico de 1999 - "Psicologia e Compromisso Social - Educação Inclusiva: Desafios, Limites e Perspectivas", e os artigos vencedores são publicados na primeira edição de 2000. O Prêmio Monográfico de 2000 é apresentado no número 4 de 2001, e homenageia o psiquiatra Hélio Pellegrino, com o tema: "Psicologia Clínica: Dimensões Éticas e Políticas". O tema "Pluralidade Étnica: um
18 Saem: Paulo da Silveira Rosas (PE) e Thereza Pontual de Lemos Mettel (DF) e entram: Eunice $M$. L. Soriano de Alencar (DF) e Oswaldo Yamamoto (RN). 
Desafio à Psicologia Brasileira" homenageia Arthur Ramos com o Prêmio Monográfico de 2001, cujos trabalhos vencedores estão publicados no número 4 de 2002.

O número 4 do ano 2000, com tiragem de 106.000 exemplares, é apontado como uma edição histórica por três motivos. É o primeiro número publicado após a 1 a - Mostra Nacional de Práticas em Psicologia, realizada no Centro de Convenções Anhembi, em São Paulo, em outubro. A Mostra, que teve como tema Psicologia e Compromisso Social e aproximadamente 1000 trabalhos inscritos, alcançou um sucesso absoluto. O evento "foi fundamental para apresentar a nova face da Psicologia brasileira", tendo a revista cumprido "um importante papel na divulgação da Mostra por meio das três edições publicadas nesse ano". O segundo motivo que torna esse número histórico é que ele "inaugura um período de nova periodicidade para a revista", que passa a ser trimestral. O terceiro motivo merece muita comemoração, pois vem ao encontro de um dos objetivos centrais dos idealizadores da revista:

"pela primeira vez, na sua história, Psicologia: Ciência e Profissão recebeu o melhor conceito possível na avaliação bianual da CAPES ANPEPP. A Comissão para Avaliação das Revistas Científicas em Psicologia, para o biênio 1998/2000, considerou a revista como Nacional Padrão A, nível alcançado por poucos periódicos nacionais" (PCP, 2000, vol. 20, n. 4, p. 3).

Psicologia: Ciência e Profissão, além da divulgação dos trabalhos produzidos entre nós, o que, por si só, já é uma função de extrema importância, também divulga os grandes eventos promovidos pelo Sistema Conselhos, cujo objetivo fundamental é produzir uma nova identidade para o profissional da Psicologia brasileira, alicerçada no compromisso social. No ano 2001, o evento que se destaca é o IV Congresso Nacional de Psicologia -
"Qualidade, Ética e Cidadania nos Serviços Profissionais: Construindo o Compromisso Social da Psicologia". O CNP é o espaço para se definir as "diretrizes que balizarão politicamente as ações dos Conselhos de Psicologia para o próximo triênio". Nesse evento, são apresentadas e "inscritas as chapas que concorrerão, nas próximas eleições, para o Conselho Federal de Psicologia". Diferentemente de outras profissões, o novo Plenário será eleito para implementar as diretrizes democraticamente decididas no CNP (PCP, 2001, vol. 21, n.1, p.3).

Ainda no ano 2001, uma nova política editorial está em processo de implantação, buscando "atender os interesses da maioria dos psicólogos, em cada edição planejada" e, para isso, a comissão editorial utiliza alguns critérios:

"respeitar a diversidade da população atingida (...) considerar as diferentes áreas da Psicologia abrangidas pelos textos publicados, procurar equilibrar os trabalhos de natureza científica com os relatos e discussões das práticas profissionais sem deixar de mencionar a questão das diferentes linhas teóricas subjacentes" (PCP, 2001, v.21, n. 1, p. 3).

No editorial do número 3 do ano 2001, o lugar da Psicologia: Ciência e Profissão é ressaltado no que se refere à "ampliação e renovação dos compromissos políticos visando ao crescimento da Psicologia enquanto produção de conhecimentos e prática profissionais". Da mesma forma, o texto indica a revista

"como um instrumento de democratização dos saberes e fazeres psicológicos produzidos em nosso país e, simultaneamente, como um veículo de aproximação e congregação de todos os psicólogos brasileiros" ( PCP, 2001, v. 21, n. 3, p.3).

O último número de 2001, além de apresentar os trabalhos do Prêmio Monográfico referido anteriormente, reafirma o compromisso com 
a periodicidade trimestral da revista PCP na medida em que a categoria dos psicólogos brasileiros a tem reconhecido "como um dos instrumentos mais importantes de divulgação do conhecimento produzido pela Psicologia brasileira, como ciência e profissão". Por fim, anuncia que, no ano 2002, ocorrerá a realização do I Congresso Brasileiro - Psicologia: Ciência e Profissão, promovido pelo Fórum de Entidades Nacionais da Psicologia Brasileira, para o qual convoca toda a categoria (PCP, 2001, v. 21, n.4, p.3).

O ano 2002 é um ano de transição no plano político e também para nossa revista. No plano político, destaca-se a eleição presidencial e a esperança de que essa eleição represente "a possibilidade de mudanças nas relações de desigualdade social existentes em todos os espaços institucionais deste país". O editorial do número 3 analisa o significado da eleição para os psicólogos brasileiros, considerando o compromisso da profissão com o avanço das mudanças sociais no País, na direção "de relações de trabalho mais justas e humanas" visando "ao fim das práticas de violência nas instituições". Observa que a Psicologia e os psicólogos brasileiros "têm se empenhado na luta por uma atuação profissional comprometida com uma sociedade mais justa, mais humana e menos desigual, indicando alguns caminhos a serem construídos coletivamente" (PCP, 2202, vol.22, n.3 e 4, p.3).

A transição vivida pela revista Psicologia: Ciência e Profissão diz respeito aos novos formatos, eletrônico e on-line, acrescentados ao tradicional impresso. Os quatro números impressos de 2002 são os últimos entregues a todos os psicólogos brasileiros. Nesse ano, a tiragem da revista atinge 123.000 exemplares. A partir de 2003, as versões eletrônica e online são as únicas disponíveis para toda a categoria. A revista impressa passa a ter uma tiragem de 2000 exemplares, entregues às bibliotecas brasileiras e instituições cadastradas na Rede Brasileira de Bibliotecas em Psicologia (PCP, 2202, vol.22, n.3 e 4, p.3).
No editorial do número 2 de 2002, a psicóloga Marilene Proença, a nova editora responsável, parabeniza a gestão anterior, coordenada por Sérgio Leite, "pelo excelente trabalho realizado e ressalta que o cuidado com a publicação da revista PCP permitiu sua indexação na Base de Dados LILACS, ampliando as consultas para os profissionais psicólogos latino-americanos". Ela afirma o compromisso da nova gestão com a continuidade desse trabalho de qualidade, contando com a colaboração de todos (PCP, 2002, vol.22, n.2, p.3).

Durante os últimos anos, como referido anteriormente, o número de consultores ad hoc cresceu significativamente para atender à diversidade temática dos artigos enviados para publicação. Nesse ano de 2002, em especial, a diversidade reflete a inserção da Psicologia em múltiplos campos de ação: programa de saúde da família; drogas e trabalho; novas tecnologias de comunicação; saúde coletiva; etnia e religiosidade; formação de psicólogos; produção de subjetividades; ecologia; identidade e alteridade; educação; movimentos sociais; psicanálise; Psicologia jurídica; saúde do trabalhador; Psicologia e saúde; trânsito. Os trabalhos publicados versam sobre temas atuais da realidade brasileira,

"possibilitando aos psicólogos conhecer a amplitude das áreas de atuação/formação de psicólogos no Brasil. Consideramos que tais artigos destacam a relevância do trabalho psicológico frente a desafios educacionais, sociais e políticos, presentes na atualidade, apresentando alternativas viáveis de intervenção em diversas questões da realidade social brasileira" (PCP, 2002, v.22.,n.2, p.3).

Os editoriais dos anos 2003 e 2004 priorizam análises referentes às transformações tecnológicas da revista bem como os efeitos dessas transformações para a Psicologia como ciência e profissão no Brasil. Ao lado da ênfase dada a esse aspecto, destacam temas 
analisados por alguns dos artigos publicados. No número 1 de 2003 são apresentadas as razões que levaram às mudanças na forma de apresentação de Psicologia: Ciência e Profissão aos psicólogos brasileiros. Cientes da diversidade de áreas de atuação e de formação dos psicólogos, o Sistema Conselhos se pergunta "que informações veicular ao profissional e ao estudante de Psicologia". E também se pergunta sobre a forma de veicular essas informações, considerando "o crescente número de psicólogos e estudantes de Psicologia no País". Para responder a essas questões, o Sistema Conselhos e o CFP se propõem a dois desafios: ampliar o conjunto de publicações a ser veiculado ao psicólogo brasileiro e estudantes de Psicologia bem como incluir formas virtuais de veiculação dessa informação. Para isso, além da revista PCP, que continuará a ter 4 edições, serão publicadas 2 edições de uma revista centrada na atuação profissional e "uma publicação de compilação da produção nacional em determinada temática". Essas mudanças são encaradas como um desafio, cujos ganhos serão maiores, na medida em que será possível aumentar o número de artigos publicados, "incluir novas seções, apresentar o texto com maior agilidade, com "links" para outros meios virtuais de informação, como a rede BVS PSI" e ampliar o acesso à revista. Os artigos publicados não são citados no editorial (PCP, 2003, vol.23, n.1, p.3).

O número 2 de 2003 focaliza a diversidade dos temas abordados, nas áreas de educação infantil, saúde, formação profissional, bem como temáticas centrais na Psicologia, como as emoções e o preconceito. A abordagem dos temas é feita tanto do ponto de vista teórico quanto da prática profissional. Os títulos dos artigos e seus autores constam do editorial (PCP, 2003, vol.23, n.2, p.3). Os artigos apresentados no número 3 de 2003 destacam elementos para uma reflexão crítica a respeito da formação e da atuação profissional, dando ênfase à presença do psicólogo em vários campos na área da saúde e também à diversidade de áreas de atuação no campo social, o que apresenta questões importantes para reflexão.

O último número de 2003 chama a atenção para o lugar do Congresso Nacional de Psicologia - CNP - em sua V edição - instância democrática onde são discutidos os rumos da profissão, definidos a partir das teses que se tornam diretrizes a serem seguidas pelos futuros dirigentes do Sistema Conselhos. Destaca-se a importância de envolver as novas gerações, "por meio da participação estudantil, da formação política desses jovens", contribuindo, assim, para o fortalecimento da profissão, considerando-se que a Psicologia tem hoje a perspectiva do compromisso social, enquanto ciência e profissão, delimitando ações e ampliando possibilidades na relação com os problemas sociais a serem enfrentados (PCP, 2003, vol.23, n.4, p.3).

Os últimos números até agora publicados são os do ano 2004. No número 1, o editorial destaca a participação do Conselho Federal de Psicologia na terceira edição do Fórum Mundial de Educação, enfatizando que o Fórum responde a "um movimento da sociedade brasileira, ou de parte dela, que se dispõe a discutir as temáticas da diversidade e da inclusão sociais". Esse movimento "aponta um caminho que questiona as tendências mais conservadoras de nossa sociedade, centradas nos conceitos de normalidade, padronização e classificação", indicando a necessidade de que os psicólogos contribuam para superar "mazelas sociais e educacionais". Somam-se a esse movimento questões postas pela Psicologia e outras áreas das Ciências Sociais na direção de "recuperar a história das formas institucionais que conformam determinadas subjetividades em todos os campos sociais, incluindo a educação". O editorial destaca o lugar da Psicologia na análise "do processo perverso de criação da identidade social do deficiente, do interno por ato infracional, do 
preso, do doente mental", perversidade essa que participa "de uma mesma lógica de compreensão da realidade social, marcada pela segregação, pela intolerância, pela discriminação. Como romper essa lógica? Como construir práticas sociais e psicológicas que contribuam para a constituição de outros processos subjetivos?" Ainda que o editorial afirme que os trabalhos apresentados analisam o tema do Fórum Mundial de Educação, isso não aparece nos artigos, com exceção de um deles, cujo título é: "Sobre a retórica da exclusão: a incidência do discurso ideológico em serviços substitutivos de cuidado a psicóticos". Os outros artigos versam sobre os seguintes temas: idoso institucionalizado; formação de psicodramatista; Psicologia hospitalar; Gestalt-terapia; maternidade e modernidade; corpo e Psicologia social; agressividade e psicanálise; psicanálise e acompanhamento terapêutico; da modernidade para a pós-modernidade no plano do indivíduo; Psicologia e genética; Psicologia e prevenção ao abuso de drogas; exclusão e reforma psiquiátrica no Brasil (PCP, 2004, vol.24, n.1, p.3).

O número 2 de 2004 registra uma ampliação do número de consultores ad hoc em resposta às novas áreas dos artigos enviados para publicação, tais como: neurociências, intervenções na área da saúde, políticas públicas e psicossomática, enfatizando a necessidade de aperfeiçoar a redação dos resumos e abstracts por sua importância na disseminação da informação no cenário internacional. O editorial refere-se também à participação na $8^{\text {a }}$ Conferência sobre Publicações Eletrônicas, realizada em Brasília, o que "inspirou a realização do I Encontro de Editores de Revistas Científicas em Psicologia e a criação da Associação de Editores de Revistas Científicas Nacionais em Psicologia". Essa associação é a "pedra fundamental para disponibilizar on line todos os periódicos em Psicologia do Brasil, que assim o quiserem, por meio do sistema da BVS - Psi, com metodologia BIREME". O editorial não faz referência aos artigos publicados, mas sim aos avanços tecnológicos da ciência do conhecimento bem como do lugar que a revista PCP do CFP ocupa nessa área, no Brasil (PCP, 2004, vol. 24, n.2, p.3) .

O tema "direitos humanos e atuação da Psicologia brasileira", em especial o lugar da Comissão de Direitos Humanos do CFP, é destacado no editorial do terceiro número de 2004. Dentre os artigos publicados, um deles trata do tema. Por fim, no número 4 desse ano, a revista apresenta uma temática inovadora na discussão acadêmica/formação profissional: comunicação social. É recente a discussão da importância da comunicação social na constituição da subjetividade humana, da cultura e das relações interpessoais. Nesse número, são apresentados os trabalhos do Prêmio Monográfico Dante Moreira Leite, com a temática "Psicologia e Comunicação Social: produção de sujeitos, subjetividades e identidades culturais". A editora responsável, Marilene Proença, despede-se da função, que, a partir dessa época, será assumida pela Conselheira Acácia Aparecida Angeli dos Santos.

\section{Conclusão}

A partir do estudo dos 25 anos de publicação da revista Psicologia: Ciência e Profissão, foi possível acompanhar as transformações pelas quais passou esse campo do saber fazer, no Brasil das últimas décadas. Tanto vimos ampliarse, o campo de atuação do psicólogo quanto sua produção de saber - de uma publicação com dificuldades de manter sua periodicidade, que recebia um número tão pequeno de artigos que, em muitos anos, publicou um só exemplar, onde foram reunidos os números planejados para aquele período, para uma publicação com um volume tão grande de artigos enviados para análise que, além de sua comissão editorial, cria um corpo de 
consultores ad hoc, inicialmente com sete membros, chegando, em 2004, com oitenta e um membros das múltiplas áreas de atuação e pesquisa. Refletindo o crescimento da categoria dos psicólogos, a revista passa de uma tiragem de 50.000 exemplares, na década de 1980, a 123.000, em 2002, último ano em sua versão impressa, e é entregue a todos os psicólogos inscritos nos Conselhos Regionais de Psicologia e no Conselho Federal.

No plano político ideológico, a Psicologia brasileira produziu, no período histórico em análise, uma identidade comprometida com o social, revertendo aquela que, no início dos anos 1980, a apresentava como uma profissão de elite, pouco acessível às camadas da população menos favorecidas social e economicamente. A revista não só reflete essa produção como também participa ativamente dela, divulgando os inúmeros eventos promovidos pelo Sistema Conselhos, cujo objetivo central é levar a Psicologia aos diferentes brasis bem como levar os psicólogos e estudantes de Psicologia a esses brasis que, de diversas formas, explicitam a demanda por assistência psicológica.

Atentos às mudanças socioculturais do mundo globalizado, os produtores da revista buscam formatos que possibilitem um aprofundamento do diálogo com a categoria. Impressa, em formato eletrônico e on-line, Psicologia: Ciência e Profissão comemora seus 25 anos ultrapassando as fronteiras do Brasil, levando nosso saber fazer para além mar!

Parabéns a todos os que participaram desse processo e, em especial, aos psicólogos brasileiros que, nessas últimas décadas, produziram uma Psicologia comprometida com o social, politicamente participante, que escuta todas as camadas sociais e constrói práticas para os diversos campos da vida humana, apoiadas no acolhimento das diferenças individuais e socioculturais. 
Tabela 1 - Tiragem da revista Psicologia: Ciência e Profissão (1979-2002)

\begin{tabular}{|l|l|}
\hline Edição & Número de exemplares \\
\hline $1979-1984$ & Sem informação \\
\hline $1985-1986$ & 50.000 \\
\hline $1987(1)$ & 55.000 \\
\hline $1987(2)-1990(1)$ & 64.000 \\
\hline $1990(2,3,4)$ & 73.000 \\
\hline $1991(1,2,3,4)-1992(1,2)$ & 75.000 \\
\hline $1992(3,4)$ & 78.000 \\
\hline $1993(1,2,3,4)$ & 85.000 \\
\hline $1994(1,2,3)$ & 87.000 \\
\hline $1995(1,2,3)$ & 90.000 \\
\hline $1996(1,2)$ & 93.000 \\
\hline $1996(3), 1997(1,2,3)$ & 98.000 \\
\hline $1998(1,2)$ & 99.000 \\
\hline $1998(3), 1999(1,2)$ & 102.000 \\
\hline $1999(3)$ & 103.000 \\
\hline $2000(1,2,3,4)$ & 106.000 \\
\hline $2001(1,2,3)$ & 109.000 \\
\hline $2001(4), 2002(1,2)$, & 117.000 \\
\hline $2002(3)$ & 123.000 \\
\hline
\end{tabular}

Fonte: exemplares da revista, 1979-2002 e Conselho Federal de Psicologia.

BERNARDES, L. H.G. Subjetividade: um Objeto para uma Psicologia Comprometida com o Social. Tese em Educação. Faculdade de Educação, Universidade Federal de Minas Gerais, Belo Horizonte, 2005, $337 \mathrm{f}$

CONSELHO FEDERAL DE PSICOLOGIA. Revista Psicologia: Ciência e Profissão - Normas para Apresentação de Contribuições. Brasilia, DF, s/d.

\section{Regina Helena de Freitas Campos \\ E-mail:regihfc@terra.com.br \\ Lúcia Helena Garcia Bernardes \\ E-mail:Ihgbernardes@uol.com.br}

Recebido 30/09/05 Aprovado 20/12/05

CONSELHO FEDERAL DE PSICOLOGIA. Quem é o Psicólogo Brasileiro. São Paulo: EDICON, 1988.

PSICOLOGIA: CIÊNCIA E PROFISSÃO, Braślia, DF, 1979-2004.

SALDANHA, Arthur M. Nossa Revista. Psicologia: Ciência e Profissão, n. 0. Brasília, 1979, pp. 1-3, (e

Referências 